\title{
Millennium Development Goals progress report
}

\author{
R M Beattie, ${ }^{1} \mathrm{~N} J$ Brown, ${ }^{1} \mathrm{H}$ Cass $^{2}$
}

${ }^{1}$ Archives of Disease in Childhood, BMA House, London, UK

${ }^{2}$ Royal College of Paediatrics and Child Health, London, UK

\section{Correspondence to} Dr R M Beattie, Editor in Chief, Archives of Disease in Childhood, BMA House, Tavistock Square, London WC1H 9JR, UK;

editor.adc@bmj.com

Received 21 November 2014 Revised 25 November 2014 Accepted 28 November 2014
This supplement reflects on the progress made towards the achievement of the Millennium Development Goals (MDG), with particular respect to child health. The goals, adopted by 189 countries, were set by the United Nations in 2000 and related to what could be achieved by 2015 . They highlighted a set of specific targets. They related to key themes-eradication of extreme poverty and hunger, achieve universal primary education, promote gender equality and empower women, reduce child mortality, improve maternal health, combat HIV/AIDS, malaria and other diseases, ensure environmental sustainability and develop a global partnership for development. These goals arose by necessity from concern, commitment and consensus with a shared goal to improve global health.

These targets were set against a 1990 baseline and aimed for a minimum acceptable improvement by 2015 . Those of most relevance to child health included MDG 4, the reduction of child mortality by two-thirds, and MDG 2, the provision of and accessibility to primary schooling for all children.

There have been some notable successes. Despite population growth, the number of deaths in children under 5 years of age worldwide declined from 12.7 million in 1990 to 6.3 million in 2013, which translates to about 17000 fewer children dying each day. Enrolment in primary education in developing regions reached $90 \%$ in 2010, up from $82 \%$ in 1999, which means more children than ever are attending primary school, although in 2011, 57 million children of primary school age were still out of school. The world has achieved equality in primary education between girls and boys, but few countries have achieved that target at all levels of education. In many countries, gender inequality persists and women continue to face discrimination in access to education, work and economic assets, and participation in government. For example, in every developing region, women tend to hold less secure jobs than men, with fewer social benefits. Furthermore, most progress has been made in the wealthier strata, the poorest families remaining the most vulnerable.

There are many future challenges. The MDGs will be superseded by the Sustained Development
Goals, and it will be essential to maintain the spirit of the eight themes and to keep children firmly on the agenda with ambitious new targets tackled innovatively with continued backing by the international community.

In this supplement, we have asked experts to review specific themes relevant to children and have also included reports of progress in achieving the MDGs from each of the continents. We have included review articles on abolishing inequity in order to realise child mortality targets; policies, politics and the right to child health; female literacy; initiatives to reduce maternal mortality; perinatal care; child malnutrition; essential medicines; injury prevention; reducing preventable deaths from pneumonia and diarrhoea; immunisation; HIV/AIDS and malaria. There are regional reports on progress from Europe, sub-Saharan Africa, North America, Central America, South America, Southern Asia, Southeast Asia and Oceania.

There is much still to be done. The real challenges are how to build on achievements and what to do next. There is a real necessity to reduce global conflict-religious, economic and territorial. There is a real need to better use the resources available to us.

Archives of Disease in Childhood and the Royal College of Paediatrics and Child Health are committed to increasing knowledge and awareness of specific issues through this supplement and the global child section of the journal. ${ }^{1-3}$ It is essential we all work together to improve the lot of our children and our children's children and help empower them to live in a fairer and better world.

\section{Competing interests None.}

Provenance and peer review Commissioned; internally peer reviewed.

\section{REFERENCES}

1 Alonge F, Hyder AA. Reducing the global burden of childhood unintentional injuries. Arch Dis Child 2014;99:62-9.

2 Unger CC, Salan SS, Sarker MS, et al. Treating diarrhoeal disease in children under 5: the global picture. Arch Dis Child 2014;99:273-8.

3 Yousafzai AK, Lynch P, Galdstone M. Moving beyond prevalence studies: screening and intervention for children with disability in low and middle income countries. Arch Dis Child 2014;99:840-8. 